\title{
Temática y mala praxis en los informativos de televisión en Euskadi
}

\author{
Begoña ZALBIDEA BENGOA \\ Universidad del País Vasco (UPV/EHU) \\ bego.zalbidea@ehu.es \\ Juan Carlos PÉREz Fuentes \\ Universidad del País Vasco (UPV/EHU) \\ carlos.perez@ehu.es \\ Santiago URRUTIA IZAGIRRE \\ Universidad del País Vasco (UPV/EHU) \\ santi.urrutia@ehu.es
}

Recibido: 5 de diciembre de 2014

Aceptado: 8 de mayo de 2015

\begin{abstract}
Resumen
La práctica periodística en televisión no se ajusta a los estándares éticos de exigencia profesional. El estudio de las noticias, diferenciadas entre duras y blandas, indica que las cadenas públicas son más rigurosas que las privadas en cuanto a los acontecimientos que incluyen en sus informativos: priman los relacionados con la política y la economía. El análisis de su tratamiento, por su parte, atestigua que las primeras son más laxas en cuanto al respeto de los principios deontológicos. Los resultados advierten que el sensacionalismo y la mezcla entre información y opinión son los errores que se repiten en mayor medida. Se han examinado un total de 1.928 informaciones, correspondientes a las emisiones de los noticiarios nocturnos de las seis cadenas de mayor audiencia en Euskadi: La 1, Telecinco, Antena 3, laSexta, Cuatro y ETB2.
\end{abstract}

Palabras clave: Información, calidad, ética, televisión.

\section{Hard and soft news and bad practices in television newscasts}

\begin{abstract}
The practice of journalism in television doesn't respect ethical standards of professional exigency. The selection of hard and soft news made by channels indicates that TVs of public ownership are more exigent that privately owned ones in their exercise, because news related to politics and economy have primacy in the newscasts. However, the analysis of the treatment shows the opposite: public channels are more relaxed in the fulfilment of ethical principles. Results reveal that sensationalism and not to distinguish information and opinion are the most common mistakes. A total of 1,928 news items integrating evening newscasts of the six most widely watched TV channels in the Basque Country have been examined: La 1, Telecinco, Antena 3, laSexta, Cuatro and ETB2.
\end{abstract}

Keywords: Information, quality, ethics, television.

\section{Referencia normalizada}

ZALBIDEA BENGOA, Begoña; PÉREZ FUENTES, Juan Carlos; y URRUTIA IZAGIRRE, Santiago (2015): "Temática y mala praxis en los informativos de televisión en Euskadi “. Estudios sobre el Mensaje Periodístico. Especial noviembre "Periodismo e información de calidad", págs.: 181-197. Madrid, Servicio de Publicaciones de la Universidad Complutense.

\section{Sumario}

1. Introducción. 2. ¿Información o entretenimiento?. 3. Tipo de noticias que se incluyen en los informativos. 4. El tratamiento informativo acorde con los estándares. 5. Metodología; 5.1 Muestra; 5.2 Noticias duras y blandas en los informativos de las seis cadenas; 5.3 Tratamientos inadecuados de las informaciones; 5.4 Definiciones. 6. Resultados; 6.1 Selección de noticias duras y blandas por parte de las cade- 
nas; 6.2 Tratamientos inadecuados de las noticias; 6.2.1 Proporción de casos incorrectos en el total de noticias; 6.2.2 Tipos de incorrecciones, por cadenas; 6.2.3 Temáticas más proclives a prácticas incorrectas. 7. Conclusiones. 8. Referencias bibliográficas.

\section{Introducción ${ }^{1}$}

El buen periodismo está inexorablemente ligado a la calidad informativa. Lograr que la ciudadanía reciba informaciones útiles compromete tanto a los empresarios como a los profesionales de los medios de comunicación. La razón estriba en que los hechos noticiosos son parte, y no elementos aislados, del proceso productivo en su conjunto. De ahí que la selección de los temas, su orientación, tratamiento, ubicación, duración, etc. responda a criterios previamente definidos y establecidos, y que la imposición anule el análisis y la reflexión que en toda praxis periodística debe imperar, convirtiendo el ejercicio del periodismo en una actividad rutinaria y escasamente diferenciada en sus contenidos.

Si lo que debe entenderse como una responsabilidad compartida entre periodistas, editores y empresarios concita distintas opiniones, tampoco existe una única voz que concilie lo que diferentes estudiosos e investigadores entienden por calidad. Quizá por ello, son varios los parámetros, indicadores y patrones de medición respaldados por diversos autores. Y es así porque, en opinión de Gómez y Palau (2013: 35), "la calidad periodística es la expresión de distintos procesos de obtención y gestión de la información, fruto de la aplicación de los estándares de equilibrio e imparcialidad, de contraste y pluralidad de acuerdo con los códigos éticos y las normas de autorregulación-, al tiempo que exige variedad y originalidad -en los temas y en su tratamiento-, investigación, profundización e independencia -respecto a los condicionantes políticos y las presiones económicas-".

Israel y Pomares inciden también en que la calidad de los informativos de televisión "se ve amenazada por el predominio de lo interesante sobre lo importante [...]. La naturaleza de la cadena, pública-control político o privada-control económico, la primacía de la imagen, el morbo, el conflicto o los pseudoacontecimientos dan como resultado el predominio de la emoción sobre la información de calidad" (2013: 147).

Partiendo de esas constataciones, la investigación recogida en este artículo pretende medir el grado de excelencia en la praxis periodística que las cadenas de TV de mayor audiencia en Euskadi llevan a cabo en sus noticiarios, en base al tipo de contenidos que incluyen y su forma de tratarlos. Uno de los criterios por los que se ha establecido tradicionalmente una mejor o peor consideración de las informaciones es, precisamente, el que las relaciona con la importancia que tienen en la esfera pública. En este sentido, Victoria Camps (1999:13) señala cómo el informante "elige un contenido informativo entre una serie de posibilidades, y lo hace pensando en el público al que va dirigida la información que desea transmitir".

Partiendo de lo anterior, una parte de esta investigación se centra en el análisis de las cadenas, en cuanto a qué tipos de temática seleccionan y el tiempo que dedican a

1 Este trabajo forma parte de un estudio más amplio financiado por el Ministerio de Ciencia e Innovación (CSO2009-13802-SOCI). 
los mismos, y otra se sustenta en su calidad, en función del tratamiento que dan a las informaciones desde el punto de vista de los estándares deontológicos.

El contraste de los datos provenientes de cada uno de ambos aspectos ha proporcionado resultados imprevistos, porque indican que las televisiones analizadas tienen comportamientos en apariencia contradictorios: las cadenas públicas son más exigentes que las privadas en la selección de los temas, pero se toman mayores licencias en su elaboración. Este dato necesita interpretarse teniendo en cuenta las rutinas informativas en las que se desenvuelven.

\section{2. ¿Información o entretenimiento?}

Los profesionales y las normas que regulan el ejercicio del periodismo entienden y precisan, respectivamente, que para ofrecer una información de calidad y garantizar la independencia de los periodistas debe contarse con condiciones, medios e instrumentos de trabajo adecuados y, además, percibir salarios dignos. También que las noticias y opiniones que se difunden a través de los medios de comunicación no deben estar mediatizadas por el objetivo de incrementar los índices de audiencia ${ }^{2}$. Estos y otros extremos recogidos en varios documentos, objeto de análisis y reflexión por parte de profesionales de los medios, analistas e investigadores, abundan en conceptos como los referidos a la calidad informativa, la defensa del interés público, la tendencia al entretenimiento, etc.

Respecto a la calidad informativa, en concreto, distintos autores coinciden en relacionarla con derechos y obligaciones de los emisores y receptores de las informaciones: los periodistas y la ciudadanía, respectivamente. En el estudio de esa calidad, entendida generalmente como un valor en pronunciado retroceso, pueden aplicarse diversos criterios, como la alusión al "respeto a la pluralidad y a la legalidad de la cultura nacional, la búsqueda de la innovación, o el reflejo de las diferentes opiniones y tendencias" (Gutiérrez Gea, 2000: 152-153). También, la comparación entre los contenidos televisivos y la realidad que éstos representan (López Téllez y Cuenca García, 2005: 2), así como el análisis del rigor, la pluralidad, la utilidad social de los temas que se tratan, la independencia, la neutralidad o la representatividad cualitativa y cuantitativa, entre otros indicadores (Soengas, 2013: 152).

Los periodistas Llúcia Oliva y Xavier Sitjà (2011: 59) aplican hoy en el Estado español lo que hace 14 años pronosticó en Estados Unidos otra profesional, Christiane Amanpour, cuando denunció que la "audiencia dejaba de ver informativos porque no le gustaba su contenido; es decir, el sensacionalismo irrelevante, de baja estofa, las historias amarillas y rosas, aburridas y mal explicadas, en lugar de noticias que le ayudaran a entender el mundo y a participar en la vida democrática". Para Amanpour, tal y como recogen Oliva y Sitjà (Ibíd.: 59), "las empresas de televisión son las causantes de la caída del interés del público en las noticias por hacer noticiarios pensando más en el negocio que en el derecho de los ciudadanos a la información".

2 Artículos 15 y 28 de la Resolución 1003 sobre la Ética del Periodismo, aprobada por la Asamblea Parlamentaria del Consejo de Europa, el 1 de julio de 1993. 
La traslación de esa realidad a las cadenas españolas se justifica, como en el caso de Estados Unidos, por una práctica en la que el hecho de informar ha dejado paso al infoentretenimiento, a las llamadas noticias blandas, seleccionadas con criterios de marketing y no periodísticos, donde lo importante no es servir al "derecho del público a saber" (Ibíd.: 59), sino aumentar la cuota de pantalla o, como dicen Israel y Pomares, "ver" pero "no comprender" (2013: 151).

Dader (2007: 47), por su parte, advierte que, sobre todo en las televisiones privadas, se practica cada vez más la sustitución de la actualidad política y de los asuntos de auténtica trascendencia social, económica o institucional por la nueva moda de las "noticias blandas", es decir, de las triviales, "como emanación del infoentretenimiento y el periodismo tabloidizado".

Antes, al igual que ahora, quienes desde parámetros economicistas consideraban que la información era y solo debía ser negocio creían, y siguen creyendo, que lo que atrae al público son "las noticias de proximidad, las que provocan emociones de cualquier tipo a las personas telespectadoras, las que muestran a la gente famosa y popular y lo que les sucede, así como las que explican noticias interesantes, pero intrascendentes" (Ibíd.: 60), cuando, en realidad, la ciudadanía lo que quiere es que se le ofrezcan informaciones completas: que el 'qué' vaya acompañado del 'por qué', que los hechos se presenten contextualizados y se indiquen sus consecuencias, sin olvidar que debe respetarse la verdad, existir pluralidad de fuentes, equidad..., y no morbosidad y sensacionalismo, hasta el punto de utilizar "los mismos parámetros que el espectáculo" (Langer, 2000: 12). Suárez Villegas (2014: 87) aborda también la cuestión cuando afirma que "la dinámica de un modelo de periodismo mercantilista que reduce los hechos a titulares fugaces e impactantes, como si se tratara de un eslogan publicitario, deja a la ciudadanía ayuna de la información necesaria para formarse un juicio crítico sobre los acontecimientos de interés público".

Las críticas que se hacen desde el ámbito académico sobre los contenidos de los noticiarios de televisión no encuentran paralelismo en el consumo que de los mismos se produce. Según datos del barómetro que el Centro de Investigaciones Sociológicas (CIS) realizó en marzo de 2013, el 56,8\% de la población española mayor de 18 años sigue prefiriendo el medio televisivo para informarse (2013). Además, los encuestados manifiestan que, a la hora de formarse una opinión sobre un tema, la información que reciben por ese medio les influye bastante o mucho $(36,5 \%$ y $12,1 \%$, en cada caso), siendo la economía, la política y la cultura lo que más les interesa. El grado de satisfacción que otorgan a los acontecimientos difundidos por las televisiones es medio, si bien reconocen que estas hacen que un asunto sea importante para la sociedad $(45,5 \%)$, e influyen mucho en lo que piensa la gente sobre un hecho concreto $(42 \%)$. De los profesionales del periodismo, por su parte, lo que sobre todo valoran es la objetividad y el análisis en la elaboración de las noticias $(29,2 \%)$, la formación académica $(25,4 \%)$ y que contrasten la veracidad de lo que transmiten $(21,2 \%)$.

Las opiniones vertidas y cuantificadas deben contemplarse en paralelo a la teoría que subraya que el interés público de las informaciones encierra criterios subjetivos que hacen que el receptor las perciba como útiles y, por tanto, les preste atención, las interiorice y las incorpore a su discurso y toma de decisiones (Jones, 1976: 34). En este 
sentido, indica Muñoz Torres (1989: 69), "el interés responde a la necesidad de 'saber a qué atenerse', de tener elementos de juicio adecuados acerca del entorno, para decidir correctamente, con vistas a aquello hacia lo que cada persona se encamina como fin de su vida".

Tal planteamiento podría llevar a pensar que al individuo únicamente le interesa aquello que inequívocamente afecta a su propia existencia. Sin embargo, aclara el mismo Muñoz Torres en referencia a Warren ${ }^{3}$, "es axiomático que las cosas más fascinantes para el ser humano medio son los otros seres humanos y cómo se comportan".

Aceptado el axioma anterior surge la pregunta: ¿con qué criterios se seleccionan las noticias publicables? Las respuestas pueden variar en función del enfoque desde el que se den, pero en buena parte se asemeja a lo que aporta el mismo autor cuando escribe:

"la representación narrativa tiene, por su propia naturaleza, un carácter ejemplar o paradigmático: mediante la mostración de casos singulares del obrar humano y de las acciones externas que lo acompañan, tales casos se constituyen en modelos de conducta imitables -positiva o negativamente- $o$, por lo menos, en puntos de referencia acerca de lo que conviene hacer o evitar en tal o cual situación" (Muñoz, 1989: 70).

\section{Tipo de noticias que se incluyen en los informativos}

El tipo de contenidos que los editores seleccionan para su inclusión en los informativos responden a la ya antigua división entre informaciones serias y otras que, como se ha apuntado de soslayo, están especialmente relacionadas con el pasatiempo y la evasión. Esta clasificación es la que la literatura anglosajona utiliza desde hace décadas para diferenciar entre 'noticias duras' y 'noticias blandas'. Las primeras han sido relacionadas con las que presentan un especial interés público, entendido éste como lo realmente importante para las sociedades o lo que tiene una gran trascendencia en el devenir de las mismas. Las segundas, por el contrario, si bien pueden resultar muy atractivas para las audiencias, están más vinculadas al entretenimiento y a la satisfacción de la necesidad de relación social. Esta separación ya fue contemplada en la temprana definición que hizo Tuchman en 1972, cuando apuntó que las noticias duras "precisaban de comentario y análisis", mientras que las blandas "se referían a chismes, escándalos locales (de tipo social, no político), e historias de interés humano con poca influencia más allá de su círculo cercano" (Lehman-Wilzig y Seletzky, 2010: 38).

Sin embargo, aunque se recurre muy a menudo a esta clasificación, en realidad carece de la claridad necesaria para su utilización incuestionable. Efectivamente, diversos autores han calificado como problema importante para la investigación la existencia de muy diversas definiciones y se han lanzado a la búsqueda de posibles soluciones. Así, Lehman-Wilzig y Seletzky defienden que existe la necesidad de crear una categoría intermedia entre ambas, porque consideran que la reservada a las noticias blandas ha englobado hasta el presente bloques temáticos muy heterogéneos (Ibíd.: 41). Por ello, proponen añadir un nivel denominado "noticias generales", donde

3 La cita de la que se hace eco Muñoz Torres puede verse en WARREN, Carl, Modern News Reporting, New York, Harper $R$ Brothers, 1959, 3.’ ed., p. 241 (v.o.: 1934). 
entrarían, por ejemplo, aquellas relacionadas con la salud, la ecología, los temas científicos, o las informaciones sobre personajes que tienen gran influencia en la sociedad.

Otros analistas que también han apreciado el problema intentan, sin embargo, mantener la inicial clasificación dicotómica, mediante la elaboración de un sentido estandarizado erigido en base a las diferentes dimensiones encontradas en las definiciones previas (Reinemann et al., 2012: 221). La nueva herramienta de medición que al efecto han construido propone atender a tres aspectos importantes para poder decidir si una noticia pertenece al ámbito de las duras o de las blandas: en primer lugar está la materia que se trata (temática); seguidamente los aspectos específicos que se enfatizan (enfoque); y, por último, la manera en la que los acontecimientos se presentan visual o verbalmente (estilo). Con todo, según señalan, la temática es el fundamento sobre el cual se asientan las otras dos dimensiones (Ibíd.: 232).

Para el objeto de esta investigación se ha considerado que es suficiente tener en cuenta la dimensión temática, ya que interesa lograr una polarización básica de los contenidos informativos de las cadenas estudiadas. Siguiendo el resumen que Reinemann et al. (Ibíd.: 231) han realizado acerca de la división establecida en las definiciones tradicionales erigidas alrededor de esta dimensión, se considerarán noticias duras la política, tanto interior como internacional, y la economía. Otras informaciones, como las referentes a los temas del 'corazón', familias reales, crímenes o escándalos, serán consideradas blandas.

\section{El tratamiento informativo acorde con los estándares}

En los más de tres siglos transcurridos desde el surgimiento del periodismo tal como se concibe en la actualidad, principalmente en los últimos cien años, se han materializado cientos de iniciativas tendentes a convenir o consensuar cómo deben conducirse correctamente los protagonistas intervinientes en el proceso de obtención, elaboración y difusión de la información (editores, direcciones de los medios y periodistas). Estas iniciativas comprenden desde los códigos deontológicos propiamente dichos, o las consideraciones éticas recogidas en los libros de estilo y estatutos de redacción, hasta las recomendaciones, pautas, guías, reglas, etcétera, emanadas también desde colectivos externos al mundo de la comunicación, como asociaciones de defensa de los derechos de la mujer, o de lucha contra la exclusión social, entre otras.

De igual manera, se han realizado numerosas investigaciones destinadas a conocer cómo entienden los periodistas y sus audiencias que debieran ser las prácticas correctas de los medios. Gladney (1996: 329-331) menciona más de dos decenas de estudios sobre diarios en Estados Unidos que pretendían captar valores periodísticos, preferencias de las audiencias en lo que respecta a cómo deben actuar los periódicos, cuáles debían ser las funciones de los medios, etc. En la presente investigación, sin embargo, no se trata de analizar las opiniones de las personas involucradas sino los propios contenidos informativos, tratando de detectar casos de diferentes indicadores de mala praxis.

En general, los investigadores han trabajado con listados de categorías muy diversos, dependiendo del objeto de estudio. El propio Gladney (Ibíd.: 324), por ejemplo, utilizó una relación de dieciocho en una encuesta realizada a editores y lectores: 
nueve correspondían a 'estándares organizativos', entre los que incluía aspectos como la integridad y la imparcialidad, y otros nueve a 'estándares de contenido', con elementos como la carencia de sensacionalismo y la precisión.

Para llevar a cabo la presente investigación se han creado diecisiete categorías de prácticas inadecuadas a partir de los principios recogidos en diversos códigos deontológicos. Con el fin de construir definiciones que permitieran medir las manifestaciones incorrectas de los contenidos, se realizó un importante esfuerzo de operacionalización de conceptos.

\section{Metodología}

Los objetivos generales de esta investigación han sido: a) conocer el grado de exigencia en los informativos de seis de las cadenas de televisión que se ven en el País Vasco, en base a la distribución y cuantificación de las noticias en duras y blandas; b) analizar los tratamientos impropios que esas mismas cadenas realizan en sus noticiarios.

\subsection{Muestra}

En este trabajo se han examinado los informativos nocturnos de las seis cadenas de mayor audiencia en Euskadi: dos cadenas públicas, La 1 y ETB2, y cuatro privadas, Telecinco, Antena 3, Cuatro y laSexta. Con ese fin, se elaboró una muestra de dos semanas (una por semestre) del año 2011. La primera fue la comprendida entre los días 21 y 27 de marzo, y la segunda, la del 26 de setiembre al 2 de octubre. En total se han estudiado 84 espacios -14 de cada una de las cadenas- y 1.928 noticias. En el análisis de los contenidos ofrecidos se han tenido en cuenta tanto los elementos audiovisuales como los textuales. No se han examinado ni la sección de deportes ni la información meteorológica, por entender que ambas responden a parámetros diferentes y porque, además, las propias televisiones las incluyen en bloques separados.

\subsection{Noticias duras y blandas en los informativos de las seis cadenas}

Tomando como punto de partida los 14 días que integran la muestra general, se ha procedido a seleccionar cuatro días para el recuento de las noticias duras y blandas. En cada una de las semanas se ha analizado un día laboral (miércoles) y otro día no laboral (sábado).

A continuación se han codificado los noticiarios de las seis cadenas teniendo en cuenta dos importantes variables: la temática y la duración de cada unidad informativa. Para el análisis de la primera se han prefijado las siguientes categorías: 1. Política; 2. Economía; 3. Asuntos laborales y sindicales; 4. Conflictos bélicos; 5 . Terrorismo; 6. Catástrofes; 7. Ciencia, salud y comunicación; 8 . Violencia de género; 9. Tragedias y asesinatos; 10. Sucesos y delincuencia; 11. Cultura y espectáculos; 12 . Sociedad y temas del ‘corazón'. Las ocho primeras acogen las noticias duras y el resto, las blandas.

\subsection{Tratamientos inadecuados de las informaciones}

Dado que el otro propósito de la investigación ha sido conocer el grado de (in)cumplimiento de los principales principios deontológicos de la profesión periodística, se distinguieron, entre otros aspectos, el número total de acontecimientos incluidos en los 
informativos, los ofrecidos en portada, la temática, y el tipo de tratamiento inadecuado en que incurrían.

Como se ha apuntado anteriormente, en cuanto a los malos usos detectados, se han contemplado diecisiete categorías; a saber: 1. Discriminación por origen; 2. Distorsión 3. Especulación; 4. Estereotipo de género; 5. Falta de objetividad; 6 . Falta de precisión; 7. Fuentes sin identificar adecuadamente; 8. Lenguaje malsonante; 9. No distinguir información y opinión; 10 . No distinguir información y publicidad; 11 . No respetar la dignidad de la persona; 12 . No respetar la intimidad de la persona; 13 . No respetar la intimidad del menor; 14. No respetar la presunción de inocencia; 15 . Sensacionalismo de nivel alto; 16. Sensacionalismo de nivel bajo (espectacularización); 17. Otros.

\subsection{Definiciones}

Si bien la mayoría de las categorías arriba mencionadas no necesitan descripción, a continuación se definen algunas de las más ambiguas:

- La especulación hace referencia a la práctica de introducir dentro del contexto informativo acontecimientos futuribles, que pudieran producirse o no suceder, pero que en palabras de los informadores se presentan como irrefutables, sin el menor género de dudas. Esto invita a formar una especie de juicio sobre una determinada situación, únicamente sustentada en meros indicios, muchas veces sin una base real ni datos que los justifiquen.

- En la falta de objetividad confluyen conceptos relativos a la falta de imparcialidad, neutralidad, ecuanimidad, equilibrio de los puntos de vista, etc.

- La imprecisión deja traslucir una desgana profesional, o una carencia de medios para la correcta verificación y posible corrección del contenido de los informativos. Incide en la discrepancia entre los datos ofrecidos, ya sean de carácter numérico, de ubicación del acontecimiento, de identidad de los protagonistas...

- Con respecto al sensacionalismo, entendido como la tendencia a exagerar la importancia real de los hechos y a producir sensación o emoción en el ánimo de los receptores con noticias de impacto, se ha considerado necesario distinguir dos grados o niveles, en atención a su mayor o menor gravedad. Dentro del primero, al que se le ha denominado 'sensacionalismo de nivel alto', entran los juegos de palabras de gusto dudoso, metáforas y comparaciones gruesas, comentarios maliciosos, otros que buscan ridiculizar, caricaturizar y, muy especialmente, la descripción de detalles morbosos y sórdidos. El segundo lo conforma el 'sensacionalismo de nivel bajo' o espectacularización, donde se han incluido aquellos contenidos con tendencia a crear espectáculo de los hechos, muchas veces intrascendentes, utilizando para ello recursos como el empleo de terminología bélica, o mediante el énfasis en algo trivial para referirse a un problema de calado.

\section{Resultados}

Los resultados que se presentan responden a las dos cuestiones principales planteadas: cómo se diferencian las cadenas en lo referente a la distribución de las noticias entre duras y blandas, y cuáles son las malas prácticas que se realizan en dichas informaciones. 


\subsection{Selección de noticias duras y blandas por parte de las cadenas}

Como se ve en la tabla 1, hay grandes divergencias entre las seis cadenas en lo que se refiere al número de noticias duras y blandas que integran en sus informativos.

Tabla 1. Cadenas y proporción de noticias duras y blandas. Fuente: elaboración propia.

\begin{tabular}{|l|r|r|r|r|}
\cline { 2 - 5 } \multicolumn{1}{c|}{} & \multicolumn{2}{c|}{ Noticias duras } & \multicolumn{2}{c|}{ Noticias blandas } \\
\hline Cadena & \multicolumn{1}{c|}{$\mathbf{n .}^{\mathbf{0}}$} & \multicolumn{1}{c|}{$\%$} & \multicolumn{1}{c|}{$\mathbf{n}^{\mathbf{0}}$} & \multicolumn{1}{c|}{$\%$} \\
\hline La 1 & 80 & 81,6 & 18 & 18,4 \\
\hline ETB2 & 68 & 73,9 & 24 & 26,1 \\
\hline Antena 3 & 61 & 67,0 & 30 & 33,0 \\
\hline laSexta & 48 & 57,8 & 35 & 42,2 \\
\hline Cuatro & 57 & 56,4 & 44 & 43,6 \\
\hline Telecinco & 54 & 54,5 & 45 & 45,5 \\
\hline Total & $\mathbf{3 6 8}$ & $\mathbf{6 5 , 2}$ & $\mathbf{1 9 6}$ & $\mathbf{3 4 , 8}$ \\
\hline
\end{tabular}

En cuanto a la selección del número de noticias duras, se puede establecer una clara división entre las seis emisoras: por una parte están las públicas, que incluyen una proporción mayor que las privadas en lo que a ellas respecta, sobre todo La 1. Así, esta cadena seleccionó sólo 18 noticias blandas frente a 80 duras $(81,6 \%)$, mientras que ETB2 incluyó 24 y 68 (73,9\%), respectivamente. Por su lado, entre las privadas, Antena 3 es la que se asemeja al proceder de las públicas, al ofrecer un $67 \%$ de noticias duras. El resto se muestra bastante alejado de esta pauta, aunque en todas ellas se supera la mitad: $57,8 \%$ en laSexta, $56,4 \%$ en Cuatro y, finalmente, $54,5 \%$ en Telecinco.

En esta distribución se cumple, por tanto, lo que sería esperable en lo concerniente al comportamiento diferenciado de las cadenas públicas y privadas. A priori, se confía en que las primeras respondan más adecuadamente a la vocación de servicio público e incluyan una mayor cantidad de temas tradicionalmente considerados importantes desde el punto de vista del interés general (como la política o la economía). Por eso mismo, también pudiera preverse que las segundas incluyeran un número superior de informaciones relacionadas con el entretenimiento y la evasión.

Tabla 2. Cadenas y porcentaje de tiempo dedicado a las noticias duras y blandas.

Fuente: elaboración propia.

\begin{tabular}{|c|c|c|}
\hline Cadena & $\begin{array}{c}\% \text { de noticias } \\
\text { duras }\end{array}$ & $\begin{array}{c}\begin{array}{c}\% \text { de noticias } \\
\text { blandas }\end{array} \\
\end{array}$ \\
\hline La 1 & 81,6 & 18,4 \\
\hline ETB2 & 73,5 & 26,5 \\
\hline Antena 3 & 65,3 & 34,7 \\
\hline Cuatro & 60,0 & 40,0 \\
\hline laSexta & 52,2 & 47,8 \\
\hline Telecinco & 51,5 & 48,5 \\
\hline Total & 63,9 & 36,1 \\
\hline
\end{tabular}


La clasificación establecida anteriormente se repite casi con exactitud en lo que respecta al tiempo que dedican las cadenas a ambos tipos de noticias (tabla 2). Las diferencias son igualmente significativas entre las públicas y las privadas: La 1 ofrece más de las cuatro quintas partes de su duración a las noticias duras $(81,6 \%)$ y ETB2 hace lo mismo con casi las tres cuartas partes $(73,5 \%)$. De forma similar, todas ellas destinan mayor minutaje a las noticias duras que a las blandas.

Dentro de las privadas, Antena 3 es la que más espacio otorga a las noticias duras $(65,3 \%)$; le sigue Cuatro, con el $60 \%$, laSexta, con el $52,1 \%$ y, por último, Telecinco, que, superando justamente la mitad (51,5\%), se convierte en la emisora que mayor tiempo dedica a los temas relacionados con el ocio y el esparcimiento.

La selección de hechos noticiosos que realizan las cadenas constituye un aspecto fundamental para establecer la seriedad y nivel de exigencia de las mismas. Desde esta perspectiva, las públicas aparecen mejor situadas, mientras que los contenidos de las privadas son menos formales. La clasificación, en base a este primer criterio de noticias duras y blandas, ofrece el siguiente ranking de solvencia informativa: La 1, ETB2, Antena 3, Cuatro, laSexta y Telecinco.

\subsection{Tratamientos inadecuados de las noticias}

Para analizar el comportamiento de cada televisión en lo que respecta a la utilización de elementos no aceptables en la construcción de los contenidos desde el punto de vista de los estándares periodísticos, se han tenido en cuenta los siguientes aspectos: 1. Proporción de casos incorrectos en el total de noticias; 2 . Tipos de incorrecciones, por cadenas; 3 . Temáticas más proclives a prácticas incorrectas.

\subsubsection{Proporción de casos incorrectos en el total de noticias}

Las cadenas varían en gran medida en lo que se refiere al número de noticias que incluyen en sus informativos, por lo que el dato a considerar no es la cantidad absoluta de irregularidades, sino la proporción de éstos con respecto al total de piezas de cada cadena, como se muestra en la tabla 3.

Tabla 3. Proporción de casos incorrectos en cada cadena. Fuente: elaboración propia.

\begin{tabular}{|l|r|r|r|}
\hline \multicolumn{1}{|c|}{ Canal } & $\begin{array}{c}\mathbf{n}^{\mathbf{0}} \text { de } \\
\text { noticias }\end{array}$ & $\begin{array}{c}\mathbf{n}^{\mathbf{0}} \text { de casos } \\
\text { incorrectos }\end{array}$ & \% \\
\hline ETB2 & 369 & 87 & $\mathbf{2 3 , 6}$ \\
\hline Telecinco & 262 & 51 & $\mathbf{1 9 , 5}$ \\
\hline La 1 & 404 & 51 & $\mathbf{1 2 , 6}$ \\
\hline Cuatro & 301 & 28 & $\mathbf{9 , 3}$ \\
\hline laSexta & 304 & 26 & $\mathbf{8 , 6}$ \\
\hline Antena 3 & 288 & 20 & $\mathbf{6 , 9}$ \\
\hline
\end{tabular}

ETB2 lidera la clasificación relativa a la proporción de prácticas inapropiadas con respecto al número de noticias: casi la cuarta parte de ellas presenta algún aspecto problemático o discutible. Le sigue Telecinco, donde cerca de la quinta parte tiene un 
tratamiento inadecuado. Después, muy alejada, figura La 1, con 12,6\%. No llegan al $10 \%$ Cuatro, laSexta y Antena 3. Esta última presenta el menor porcentaje, sin llegar al $7 \%$. Existe, por lo tanto, una gran diferencia entre las que cumplen en mayor y menor medida los estándares informativos establecidos.

A modo de hipótesis, sería de suponer que las cadenas más serias en lo que se refiere a la selección de noticias fueran las que presentaran una menor cantidad de ejemplos contrarios a las normas. Sin embargo, como se desprende del párrafo anterior, una de las públicas (ETB2) lidera el ranking de usos incorrectos, mientras que la otra, La 1 , se coloca en tercer lugar, tras la privada Telecinco, aunque muy alejada de las dos primeras. La pregunta que surge es si existe alguna razón por la que las públicas tienen mayor tendencia a incumplir las normas que las privadas. Una posible respuesta sería que las temáticas duras, de las que las públicas se nutren especialmente, fueran más proclives a la vulneración. ¿Es esto así?

Si tenemos en cuenta los datos de todas las televisiones (tabla 4), casi dos tercios de los casos corresponden a temáticas duras $(63,1 \%)$, mientras que algo más de un tercio se dedica a las blandas $(36,9 \%)$. Resulta sorprendente constatar que esto iguala casi con exactitud el tiempo dedicado a las noticias duras y blandas por el conjunto de las seis cadenas, cuyos porcentajes son $63,9 \%$ y $36,1 \%$, respectivamente. En concreto, las públicas presentan una distribución de incorreciones en noticias duras y blandas bastante acorde con el tiempo que dedican a cada una de ellas, por lo que se puede decir que la temática no influye directamente en el mayor o menor grado de mala praxis.

Tabla 4. Porcentajes de tiempo y de casos de mala praxis en las noticias duras y blandas.

Fuente: elaboración propia.

\begin{tabular}{|l|r|r|r|r|}
\cline { 2 - 5 } \multicolumn{1}{c|}{} & \multicolumn{2}{c|}{ Noticias duras } & \multicolumn{2}{c|}{ Noticias blandas } \\
\hline Cadena & $\begin{array}{c}\text { \% de } \\
\text { tiempo }\end{array}$ & $\begin{array}{c}\text { \% de mala } \\
\text { praxis }\end{array}$ & $\begin{array}{c}\text { \% de } \\
\text { tiempo }\end{array}$ & $\begin{array}{c}\text { \% de mala } \\
\text { praxis }\end{array}$ \\
\hline La 1 & 81,6 & 74,0 & 18,4 & 26,0 \\
\hline ETB2 & 73,9 & 72,5 & 26,1 & 27,5 \\
\hline Antena 3 & 67,0 & 80,0 & 33,0 & 20,0 \\
\hline laSexta & 57,8 & 53,8 & 42,2 & 46,2 \\
\hline Cuatro & 56,4 & 71,4 & 43,6 & 28,6 \\
\hline Telecinco & 54,5 & 31,4 & 45,5 & 68,6 \\
\hline Total & $\mathbf{6 3 , 9}$ & $\mathbf{6 3 , 1}$ & $\mathbf{3 6 , 1}$ & $\mathbf{3 6 , 9}$ \\
\hline
\end{tabular}

Sin embargo, la temática pudiera tener consecuencias indirectas en el tratamiento. La inclusión de un número mucho mayor de noticias duras, relacionadas sobre todo con la política en sus diferentes niveles, resultaría, en principio, menos atractiva para la audiencia que la recepción de elementos para el entretenimiento, y ello propiciaría que las cadenas públicas tendieran a 'ablandarlas' con ayuda de elementos como la 'espectacularización'. 


\subsubsection{Tipos de incorrecciones por cadenas}

Las incorrecciones que abundan a nivel general son el 'sensacionalismo de nivel bajo' (o espectacularización), seguido de 'no distinguir entre información y opinión' (tabla 5). Sumando los datos de todas las cadenas, casi la mitad de los casos inadecuados o dudosos $(48,4 \%)$ corresponden a esas dos categorías. A distancia aparecen otras como 'fuentes sin identificar adecuadamente', 'especulación', 'sensacionalismo de nivel alto', y 'falta de objetividad', que en su conjunto superan la cuarta parte del total $(28,2 \%)$. El resultado es que los seis tratamientos incorrectos apuntados concentran más de las tres cuartas partes de la mala praxis $(76,6 \%)$.

Una de las razones por las que ETB2 se halla en la cúspide de este tipo de prácticas es la masiva utilización que realiza del 'sensacionalismo de nivel bajo' (casi el $40 \%$ ). La otra pública, La 1, es precisamente la que, a continuación, emplea en mayor medida este recurso (33,3\%). Asimismo, dos privadas, Cuatro y Telecinco, arrojan datos que concluyen que más de una cuarta parte de sus irregularidades están relacionadas con ese proceder ( $28,6 \%$ y $27,5 \%$, respectivamente). En el polo opuesto se sitúa Antena 3, que nunca recurre a ello, mientras que en laSexta sólo alcanza el 11,5\%.

Sin lugar a dudas, estos resultados relativos al sensacionalismo de nivel bajo posibilitan que ambas públicas obtengan una posición superior en el listado de casos, junto con la privada Telecinco. Este recurso, tendente a hacer atractivo el texto mediante una profusa utilización de figuras y expresiones literarias, resulta aceptable para la mayoría de las audiencias y, también, para el conjunto de la profesión periodística. De hecho, si se analizaran los distintos tipos de mal tratamiento desde el punto de vista de su repercusión en la calidad de las noticias, este tipo de sensacionalismo debería considerarse como el menos perjudicial, aunque un periodismo exigente recomendaría prescindir también de él.

Tabla 5. Porcentajes de malos usos en las televisiones. Fuente: elaboración propia.

\begin{tabular}{|l|r|r|r|r|r|r|r|}
\hline \multicolumn{1}{|c|}{ Malos usos } & ETB2 & Telecinco & La 1 & Cuatro & laSexta & Antena 3 & Total \\
\hline $\begin{array}{l}\text { Sensacionalismo de nivel bajo } \\
\text { (espectacularización) }\end{array}$ & 38,8 & 27,5 & 33,3 & 28,6 & 11,5 & 0,0 & $\mathbf{2 8 , 5}$ \\
\hline $\begin{array}{l}\text { No distinguir información y } \\
\text { opinión }\end{array}$ & 25,0 & 15,7 & 17,6 & 17,9 & 19,2 & 20,0 & $\mathbf{1 9 , 9}$ \\
\hline $\begin{array}{l}\text { Fuentes sin identificar } \\
\text { adecuadamente }\end{array}$ & 7,5 & 2,0 & 17,6 & 0,0 & 11,5 & 5,0 & $\mathbf{7 , 8}$ \\
\hline Especulación & 13,8 & 3,9 & 7,8 & 3,6 & 3,8 & 0,0 & $\mathbf{7 , 4}$ \\
\hline Falta de objetividad & 5,0 & 15,7 & 3,9 & 0,0 & 11,5 & 0,0 & $\mathbf{6 , 6}$ \\
\hline Sensacionalismo de nivel alto & 3,8 & 5,9 & 2,0 & 14,3 & 11,5 & 15,0 & $\mathbf{6 , 6}$ \\
\hline $\begin{array}{l}\text { No respetar intimidad del } \\
\text { menor }\end{array}$ & 0,0 & 0,0 & 2,0 & 21,4 & 7,7 & 30,0 & $\mathbf{5 , 9}$ \\
\hline Falta de precisión & 3,8 & 3,9 & 7,8 & 3,6 & 0,0 & 5,0 & $\mathbf{4 , 3}$ \\
\hline $\begin{array}{l}\text { No respetar presunción de } \\
\text { inocencia }\end{array}$ & 2,5 & 2,0 & 5,9 & 7,1 & 3,8 & 5,0 & $\mathbf{3 , 9}$ \\
\hline Discriminación por origen & 0,0 & 5,9 & 0,0 & 0,0 & 7,7 & 5,0 & $\mathbf{2 , 3}$ \\
\hline Estereotipo de género & 0,0 & 5,9 & 0,0 & 0,0 & 7,7 & 0,0 & $\mathbf{2 , 0}$ \\
\hline Distorsión & 0,0 & 0,0 & 0,0 & 0,0 & 3,8 & 15,0 & $\mathbf{1 , 6}$ \\
\hline Otros & 0,0 & 11,8 & 2,0 & 3,6 & 0,0 & 0,0 & $\mathbf{3 , 1}$ \\
\hline
\end{tabular}


¿De qué tipos de prácticas se nutre la mayor parte de la mala praxis en cada cadena? En ETB2 el 'sensacionalismo de nivel bajo' (o espectacularización), 'no distinguir información y opinión' y la 'especulación’ alcanzan el 76,6\%. En Telecinco, casi el 60\% está ocupado por 'espectacularización', 'no distinguir entre información y opinión' y 'falta de objetividad'. En La 1, el 68,5\% lo conforman 'espectacularización', 'no distinguir entre información y opinión' y 'fuentes sin identificar adecuadamente'.

Las otras tres cadenas, que tienen una proporción mucho menor de usos inadecuados con respecto al número de noticias, muestran diferentes combinaciones: en Cuatro, el 67,9\% está representado por 'espectacularización', 'no respetar la intimidad del menor' y 'no distinguir información y opinión'; en laSexta, el $65,2 \%$ lo protagonizan cinco tratamientos impropios, como son "no distinguir información y opinión', 'espectacularización', 'falta de objetividad', 'fuentes sin identificar adecuadamente' y 'sensacionalismo de nivel alto'; finalmente, en Antena 3, que presenta la cantidad más pequeña de casos, estos se hallan concentrados (80\%) en las categorías 'no respetar la intimidad del menor', 'no distinguir información y opinión', 'distorsión' y 'sensacionalismo de nivel alto'.

\subsubsection{Temáticas más proclives a prácticas incorrectas}

Cuatro temáticas concentran más de dos tercios de la mala praxis: Política, Sucesos y delincuencia, Conflictos bélicos, y Sociedad y temas del 'corazón' (tabla 6). Un aspecto importante es saber si estos datos son esperables desde el punto de vista de su peso informativo.

Tabla 6. Porcentajes de noticias y malos usos en cada temática. Fuente: elaboración propia.

\begin{tabular}{|l|r|r|}
\hline \multicolumn{1}{|c|}{ Temática } & \multicolumn{1}{|c|}{$\begin{array}{c}\text { \% de noticias con } \\
\text { esta temática }\end{array}$} & $\begin{array}{c}\text { \% sobre el total de } \\
\text { malas prácticas }\end{array}$ \\
\hline Política & 36,0 & 32,8 \\
\hline Sucesos y delincuencia & 8,7 & 14,1 \\
\hline Conflictos bélicos & 6,2 & 12,9 \\
\hline $\begin{array}{l}\text { Sociedad y temas del } \\
\text { corazón' }\end{array}$ & 14,5 & 10,9 \\
\hline Resto de temas & 34,6 & 29,3 \\
\hline
\end{tabular}

Nos encontramos con dos situaciones en que los casos detectados de tratamiento inadecuado son inferiores a los que se pudiera esperar teniendo en cuenta su importancia informativa. Por un lado, se trata de un tema integrado en noticias duras y, del otro, de una categoría inserta en noticias blandas. Hablamos, en primer lugar, de Política (en sus diferentes ámbitos), que representa en conjunto casi un tercio de todos los ejemplos $(32,8 \%)$, aunque su valor en el conjunto supere esa cifra (36\%). Lo mismo sucede con Sociedad y temas del 'corazón', en la que los casos suponen el $10,9 \%$; este dato, sin embargo, es menor de lo que se podría esperar, dado que su peso en los informativos es del $14,5 \%$.

Con los otros dos grandes bloques temáticos, uno blando y otro duro, ocurre lo contrario; Sucesos y delincuencia recoge un $14,1 \%$ de los casos, mientras que su pre- 
sencia es solo del 8,7\%. Por su parte, Conflictos bélicos suma el 12,9\% de los ejemplos, a pesar de que su porcentaje del número de noticias se limita a un $6,2 \%$.

Por lo tanto, aunque algunas temáticas tengan cierta propensión a ser peor tratadas, las diferencias de porcentajes no tienen repercusión a nivel global. La divergencia no resulta significativa porque las cuatro categorías apuntadas suman el 70,7\% de los casos, mientras que su relevancia en las noticias es del $65,4 \%$.

Del total de las trece prácticas irregulares detectadas, seis están sobre todo relacionadas con las cuatro temáticas de mayor peso informativo (Política, Sucesos y delincuencia, Conflictos bélicos y Sociedad y temas del 'corazón'). Se trata de 'espectacularización', 'especulación', 'falta de objetividad', 'fuentes sin identificar adecuadamente', 'no distinguir información y opinión' y 'no respetar la intimidad del menor' (tabla 7).

Tabla 7. Porcentajes de malos usos dentro de cada temática. Fuente: elaboración propia.

\begin{tabular}{|l|r|r|r|r|r|r|r|}
\hline \multicolumn{1}{|c|}{ Temática } & $\begin{array}{c}\text { Espectacula- } \\
\text { rización }\end{array}$ & Especulación & $\begin{array}{c}\text { Falta de } \\
\text { objetividad }\end{array}$ & $\begin{array}{c}\text { Fuente sin } \\
\text { identificar } \\
\text { adecuadamente }\end{array}$ & $\begin{array}{c}\text { No } \\
\text { distinguir } \\
\text { información } \\
\text { y opinión }\end{array}$ & $\begin{array}{c}\text { No } \\
\text { respetar la } \\
\text { intimidad } \\
\text { del menor }\end{array}$ & $\begin{array}{c}\text { Suma } \\
\text { porcentual } \\
\text { sobre el total } \\
\text { de casos } \\
\text { incorrectos }\end{array}$ \\
\hline $\begin{array}{l}\text { Conflictos } \\
\text { bélicos }\end{array}$ & 15,2 & 12,1 & 18,2 & 21,2 & 21,2 & 3,0 & $\mathbf{9 0 , 9}$ \\
\hline Política & 31,0 & 9,5 & 6,0 & 7,1 & 31,0 & 7,1 & $\mathbf{9 0 , 5}$ \\
\hline $\begin{array}{l}\text { Sociedad, y } \\
\text { temas del } \\
\text { corazón' }\end{array}$ & 50,0 & 3,6 & 3,6 & 3,6 & 10,7 & 0,0 & $\mathbf{7 1 , 4}$ \\
\hline $\begin{array}{l}\text { Sucesos y } \\
\text { delincuencia }\end{array}$ & 25,0 & 5,6 & 8,3 & 5,6 & 8,3 & 2,8 & $\mathbf{5 5 , 6}$ \\
\hline
\end{tabular}

En Política, las referidas seis prácticas improcedentes ocupan el 90\% de todos los casos; en Conflictos bélicos, el 91\%; en Sociedad y temas del 'corazón', el 71\%; y finalmente, en Sucesos y delincuencia, el 56\%. Esto significa que en esta última temática confluyen un mayor número de muestras impropias. Por ejemplo, además de las seis que conforman la mayoría, aparecen, entre otras, la 'discriminación por origen' y 'no respetar la presunción de inocencia'.

Por lo tanto, cada temática parece relacionarse con determinados tipos de incorrecciones. Política y Sociedad y temas del 'corazón' las concentran en dos categorías. En la primera, los casos más abundantes corresponden a 'espectacularización' y a 'no distinguir información y opinión'. En la segunda se acentúa la 'espectacularización', seguida muy de lejos por 'no distinguir información y opinión'.

En las otras dos temáticas, en cambio, los malos usos están mucho más repartidos. El apartado referente a Sucesos y delincuencia presenta una serie de tratamientos inadecuados que, de mayor a menor, responden al siguiente orden: 'espectacularización', 'falta de objetividad', 'no distinguir información y opinión', 'especulación' y 'fuentes sin identificar adecuadamente'. Respecto a Conflictos bélicos, la relación es la siguiente: 'no distinguir información y opinión', 'fuentes sin identificar adecuadamente', 'falta de objetividad', 'espectacularización' y ‘especulación'. 


\section{Conclusiones}

Las televisiones públicas mantienen un nivel de exigencia bastante mayor que las privadas en cuanto a la selección de sus contenidos. La diferencia estriba en que las primeras ofrecen una proporción superior de noticias duras en comparación con las blandas: La 1, el 81,6\% y ETB2, el 73,9\%. De las privadas, Antena 3 recoge un número más elevado de informaciones duras $(67 \%)$, seguida de lejos por laSexta $(57,8 \%)$, Cuatro $(56,4 \%)$ y, finalmente, por Telecinco $(54,5 \%)$.

Este resultado contrasta claramente con lo que ocurre respecto a las prácticas inadecuadas, dado que, comparativamente, las cadenas públicas no destacan precisamente por el adecuado cumplimiento de los estándares informativos. De hecho, ETB2 encabeza el listado en lo referente al porcentaje de incorreciones en relación al total de noticias: casi la cuarta parte de ellas conlleva algún aspecto problemático o discutible. Le sigue Telecinco, con cerca de la quinta parte.

La otra cadena pública, La 1, se aleja de las dos anteriores $(12,6 \%)$, pero aun así presenta una cifra por encima de las tres restantes (Cuatro, laSexta y Antena 3), que no llegan al 10\%. Es decir, la mayor solvencia que se les puede atribuir a las dos cadenas públicas en función de los hechos que seleccionan, no se ve acompañada por un nivel de exigencia paralelo en lo que respecta a los buenos usos periodísticos.

Tres factores intervienen para explicar este hecho. En primer lugar, está la influencia de las temáticas serias: aunque a priori pueda pensarse que las noticias blandas son susceptibles de ser peor tratadas que las duras, el hecho de incluir muchas de este tipo provoca cierta tendencia hacia una mayor manipulación, como les ocurre a las públicas. Las privadas, por su parte, sienten menos necesidad de hacerlo, porque simplemente con seleccionar acontecimientos intrínsecamente más sensacionalistas consiguen enganchar a la audiencia. De esta forma, las dos cadenas públicas, y sobre todo ETB2, se ven abocadas a tomarse más licencias en la elaboración de los contenidos, so pena de verse consideradas como carentes de atractivo en su competencia con las privadas. La utilización profusa que hacen de determinados recursos, como la 'espectacularización' y la 'no distinción de información y opinión', ha de situarse en este contexto.

La segunda causa es la mediatización política: las cadenas públicas siguen rutinas diferentes a las de las privadas porque tienen una gran conexión con los sucesivos gobiernos, al entender éstos que la televisión está a su servicio. La necesidad de actuar de manera acorde con las directrices emanadas desde los ejecutivos se deja notar en el tratamiento, por ejemplo, en lo que respecta a la 'no distinción entre información y opinión'. Frente a esto, las privadas no se ven obligadas a seguir criterios gubernamentales, aunque cada una de ellas tenga su propio posicionamiento político.

El tercer factor sirve específicamente para explicar el caso de ETB2, que es la televisión que destaca por sus usos inadecuados, y que se refiere a su carácter comunitario. Forman parte del mismo elementos como el localismo y la cercanía con la audiencia, que se traduce en el empleo de un lenguaje más coloquial e informal para propiciar que la información sea más entretenida. Esto se consigue, entre otros recursos, mediante el aumento de la 'espectacularización' y la 'especulación'.

En cuanto a las privadas, se pueden apuntar diversas razones para explicar las diferencias existentes entre ellas. Telecinco es la que muestra un tratamiento menos exigente, porque busca maximizar la rentabilidad social, manteniendo en sus informativos 
la estela de los programas ligeros que constituyen su esencia. Es la cadena que al combinar el mayor porcentaje de noticias blandas y, tras ETB2, el tratamiento menos cuidado se convierte en la menos formal.

Al contrario que Telecinco, Antena 3 aparece como la más seria de las privadas, al concatenar una alta proporción de noticias duras -la mayor tras las públicas- con una baja de malas prácticas -la menor de todas las cadenas-.

Entre las anteriores privadas están Cuatro y laSexta: Cuatro se coloca mejor en cuanto a noticias duras, aunque peor que laSexta en el tratamiento de las informaciones. Este trato menoscaba la calidad, que desde su origen pretendió ser la seña de identidad de la primera, mientras que laSexta adoptó un posicionamiento progresista y apostó por la cultura. Todo ello justifica que esta última conceda un mayor peso a las noticias blandas, al resultar en sí mismas más llamativas para la audiencia y, consecuentemente, no precisar de enfoques espectacularizantes.

\section{Referencias bibliográficas}

CAMPS, Victoria (2001): "El qué y el cómo de la información de calidad". Quaderns del Consell de l'Audiovisual de Catalunya, no 9, p. 13.

CIS (2013). Barómetro de marzo. Estudio $\mathrm{n}^{\circ}$ 2.981, en: http://datos.cis.es/pdf /Es2981mar_A.pdf [consulta: 15 de mayo de 2014].

DADER, José Luis (2007): "Del periodista pasible, la obviedad informativa y otras confusiones en el Estanco de Noticias". Estudios sobre el Mensaje Periodístico, $\mathrm{n}^{\circ}$ 13, pp. 31-53. Madrid, Servicio de Publicaciones de la Universidad Complutense.

GLADNEY, George A. (1996): "How Editors and Readers Rank and Rate the Importance of Eighteen Traditional Standards of Newspaper Excellence". Journalism \& Mass Communication Qarterly, vol. 73, n² 2, pp. 319-331.

GÓMEZ MOMPART, Josep Lluís y PALAU SAMPIO, Dolors (2013): "El reto de la excelencia. Indicadores para medir la calidad periodística", en GÓMEZ MOMPART, Josep Lluís et al. (eds.): La calidad periodística. Teorías, investigaciones y sugerencias profesionales. Castellón de la Plana, Publicacions de la UJI, pp. 18-34.

GUTIÉRREZ GEA, Charo (2000): “Televisión y calidad: Perspectivas de investigación y criterios de evaluación". Zer, vol. 5, n 9, pp. 151-184.

ISRAEL GARZÓN, Estrella y POMARES PASTOR, Ricardo Ángel (2013): "Indicadores de calidad en los informativos de televisión", en GÓMEZ MOMPART, Josep Lluís et al. (eds.): La calidad periodística. Teorías, investigaciones y sugerencias profesionales. Castellón de la Plana, Publicacions de la UJI, pp. 147-151.

JONES, John Paul (1976): Gathering and writing the news: a reporter's complete guide to techniques and ethics of news reporting. Chicago, Nelson Hall.

LANGER, John (2000): La televisión sensacionalista. Barcelona, Paidós.

LEHMAN-WILZIG, Sam y SELETZKY, Michal (2010): "Hard News, Soft News, General News: The Necessity and Utility of an Intermediate Classification". Journalism, vol. 11, $\mathrm{n}^{\mathrm{o}} 1$, pp. 37-56. 
LÓPEZ TÉLLEZ, Antonio y CUENCA GARCÍA, Francisco Antonio (2005): “Televisión e información: análisis de los criterios de televisión de calidad en los informativos de las cadenas nacionales". Comunicar, $\mathrm{n}^{\circ}$ 25, pp. 1-10.

MUÑOZ TORRES, Juan Ramón (1989): "Por qué interesan las noticias: una aproximación a los fundamentos del interés informativo". Comunicación y Sociedad, $\mathrm{n}^{\circ}$ 2, pp. 61-82.

OLIVA, Llúcia y SITJÀ, Xavier (2011): "El descenso de la calidad de los informativos en televisión". Quaderns del CAC, n 36, pp. 59-66.

REINEMANN, Carsten et al. (2012): "Hard and soft news: A review of concepts, operationalizations and key findings". Journalism, vol. 13, n 2, pp. 221-239.

SOENGAS, Xosé (2013): "El nuevo escenario informativo en España después de la implantación de la Televisión Digital Terrestre". Ámbitos, nº 22, pp. 151-160.

SUÁREZ VILLEGAS, Juan Carlos (2014): "La verdad informativa como garantía del periodismo de calidad". Dilemata, $\mathrm{n}^{\circ}$ 14, p.85-97. 